\title{
PECULIAR APPENDAGES IN MALE PUPAE OF LEPTOTHORAX SUBDITIVUS (WHEELER) (HYMENOPTERA: FORMICIDAE)
}

\author{
By Ralf D. SchumanN \\ Technische Hochschule Darmstadt \\ Institut für Zoologie \\ Schnittspahnstr.3 \\ D-6100 Darmstadt, FRG
}

In April 1991, two complete colonies of $L$. subditivus, including about 80 ф̧, numerous larvae and one single queen each, were collected in a mountainous wood region near Monterrey (Nuevo Leon, Mexico) at an elevation of ca. $1600 \mathrm{~m}$ in dry wood sticks at the ground. The colonies were reared in the laboratory under conditions described in Buschinger (1974). After some weeks ơ రో-, ○০and $\emptyset \emptyset \emptyset-$ pupae were produced. The male pupae are remarkable because of their striking appendages.

Two translucent lateral projections, having their origin at the basis of the third femurs, arch forward around the wing buds. Their length is about $0,4 \mathrm{~mm}$ (Fig. 1). In addition, two blunt appendages, originating from the postpetiolar region, point forward, on both sides of the petiole (Fig. 1, 2). Below these projections, two short appendages on both sides of the petiole can be seen. Their length is about $0,15 \mathrm{~mm}$ (Fig. 2). The projections are translucent and filled with the pupal liquid. With higher magnification their surface appears roughly sculptured as the result of a partly thickened cuticle (Fig. 3). Histological studies have revealed that there are no cellular structures detectable inside any of these appendages. They seem to be part of the pupal cuticle (Billen, pers. comm.). In black pupae just prior to eclosion the appendages shrivel and finally vanish. In the adults no trace of the peculiar projections is detectable. Neither female nor worker pupae possess similar appendages in any stage of development.

As far as I know, comparable appendages have not been detected before in ant pupae. Larval appendages have been found.

Manuscript received 3 March 1992 


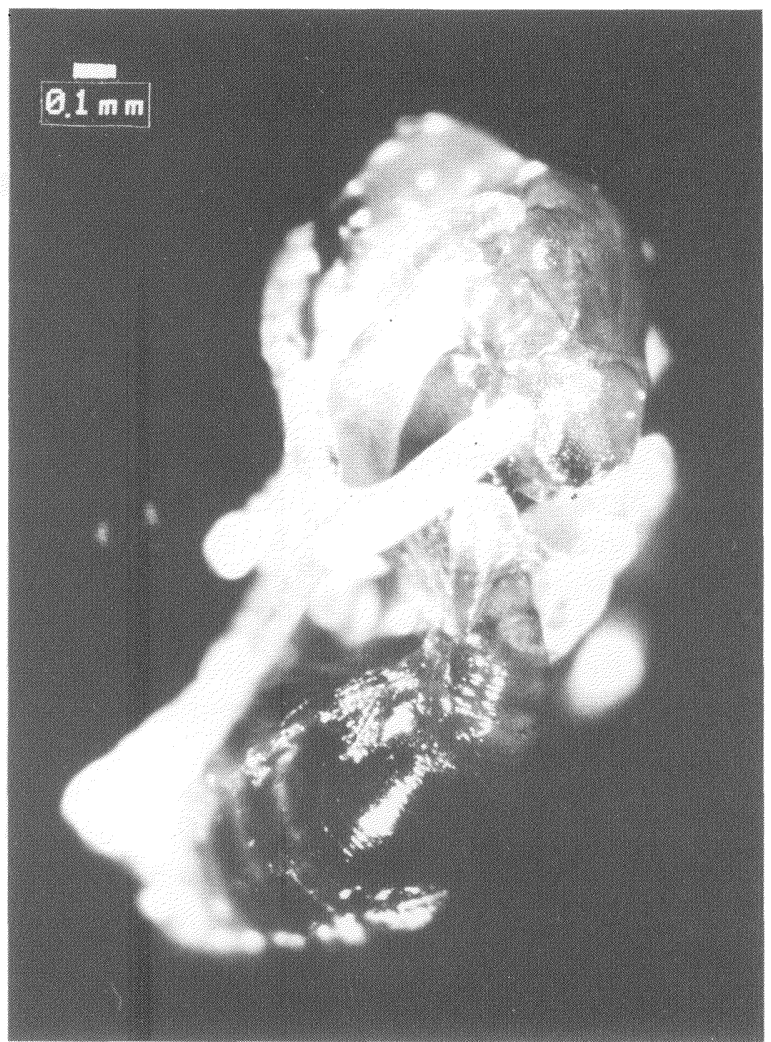

Fig. 1. Male pupa of L. subditivus, showing the left hindlegs projection and the large petiole appendages.

Wheeler (1918) described unusual thoracic and abdominal projections in larvae of Tetraponera (=Pachysima) latifrons and interpreted them as exudatoria, producing attractants for the workers. Menozzi (1930) recorded similar structures in certain Crematogaster species.

The function of the L. subditivus ơ or-pupae projections is totally unknown. Recently, I detected similar structures in male pupae of another species from the same locality, $L$. cf. tenuisculptus. Colony observations did not reveal any unusual behavior of workers or queens towards the male pupae or their appendages. Since such 


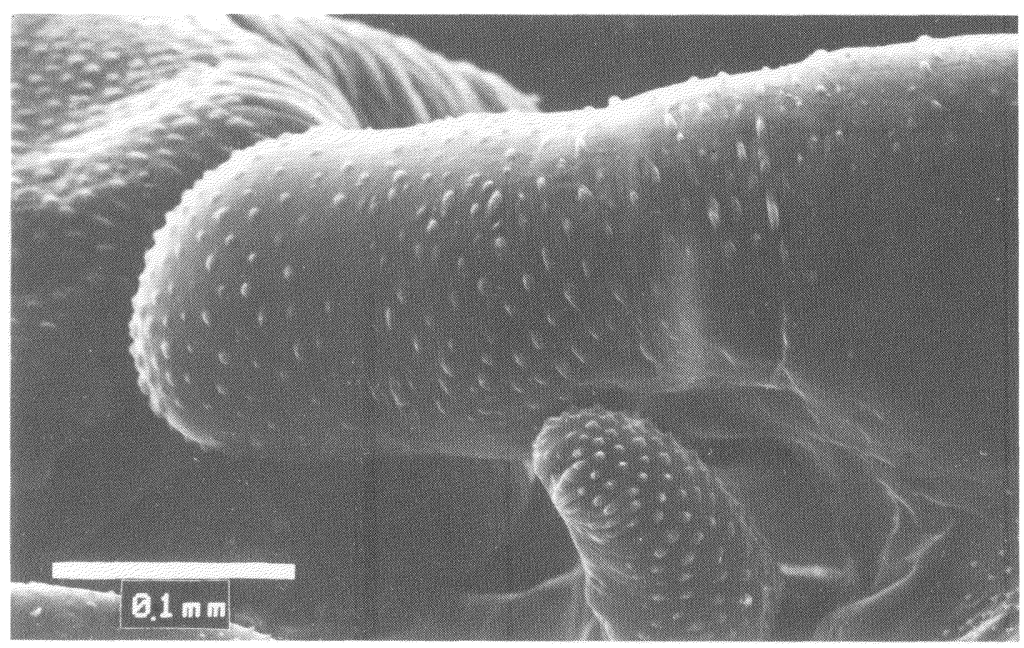

Fig. 2. Lateral view of the petiole appendages.

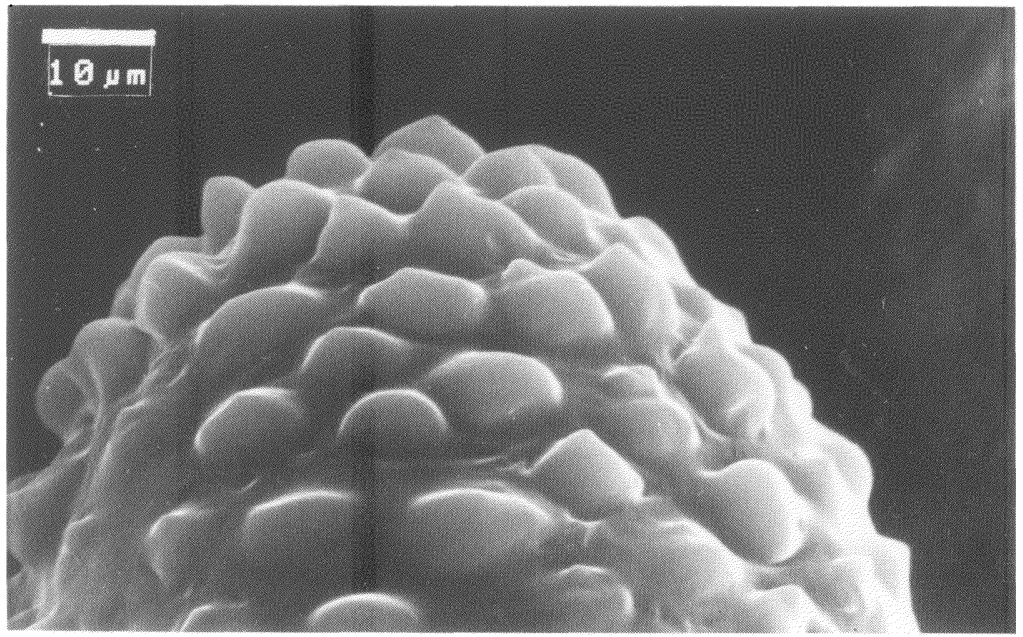

Fig. 3. With higher magnification the appendages (here the top of a hindlegs appendage) show a roughly sculptured surface. 
appendages have not been reported in male pupae of other Leptothorax, and the biology of most species in the subgenus Macromischa is very poorly known, it is possible that this trait may prove to be of taxonomic value in defining species groups within Leptothorax.

\section{SUMMARY}

The male pupae of Leptothorax subditivus (Wheeler) possess striking leg and petiole appendages which might be helpful in resolving the difficult taxonomy of the Leptothorax complex.

\section{ACKNOWLEDGEMENTS}

I want to thank C. Baroni Urbani for determining the species, J. Billen for first investigations on the material, and A. Buschinger and A. Maiazza for taking the photos.

\section{Literature Cited}

BARONI URBANI, C.

1978. Materiali per una revisione dei Leptothorax neotropicali appartenenti al sottogenere Macromischa Roger, n. comb. (Hymenoptera: Formicidae). Entomologica Basiliensia 3: 395-618.

BUSCHINGER, A.

1974. Experimente und Beobachtungen zur Gründung und Entwicklung neuer Sozietäten der sklavenhaltenden Ameise Harpagoxenus sublaevis Menozzi, C. (Nyl.). Insectes Sociaux 21: 381-406.

1930. Formiche della Somalia Italiana meridionale. Memorie della Società Entomologica Italiana 9: 76-130.

WHEELER, W. M.

1918. A study of some ant larvae, with a consideration of the origin and meaning of the social habit among ants. Proceedings of the American Philosophical Society 57: 293-343. 

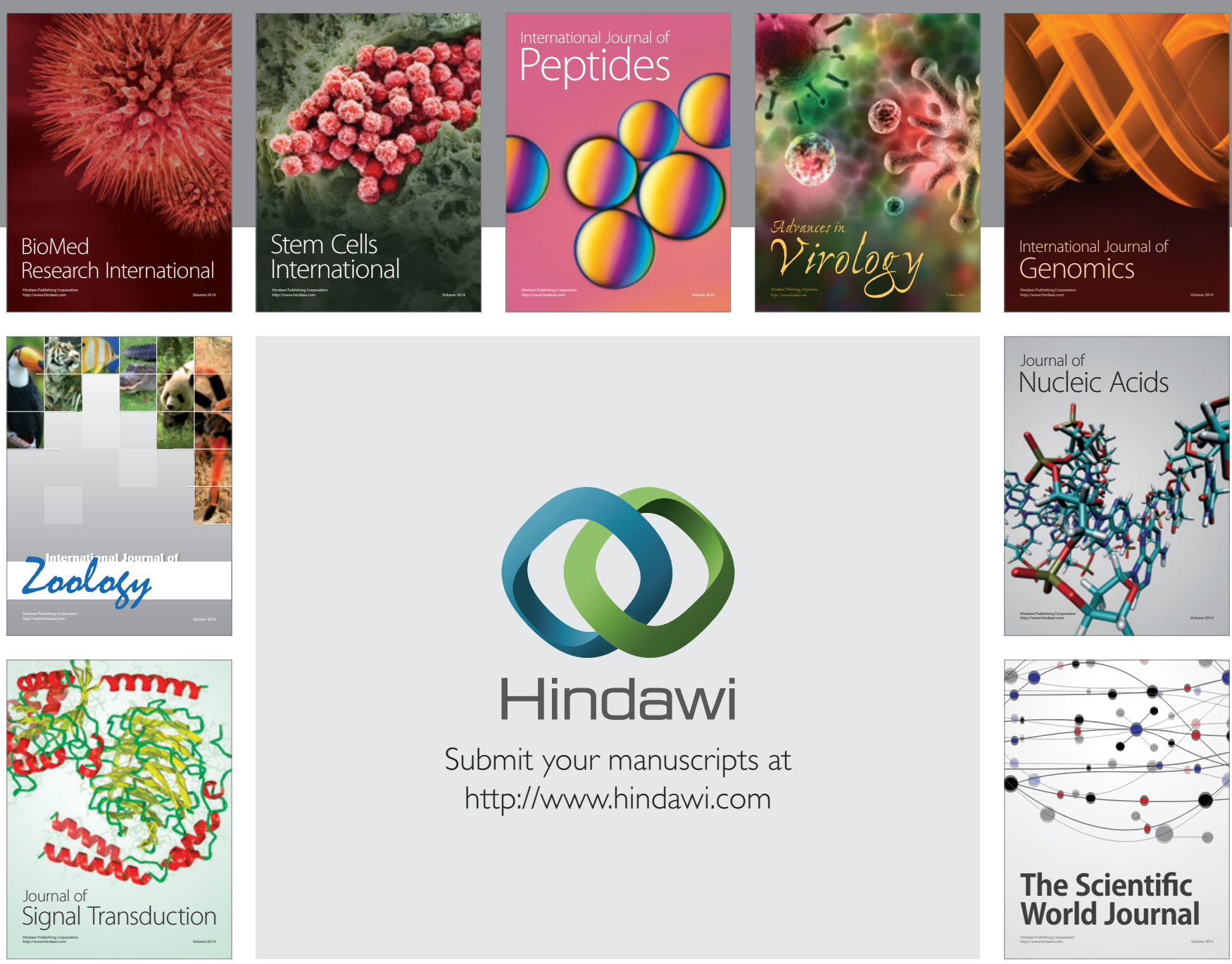

Submit your manuscripts at

http://www.hindawi.com
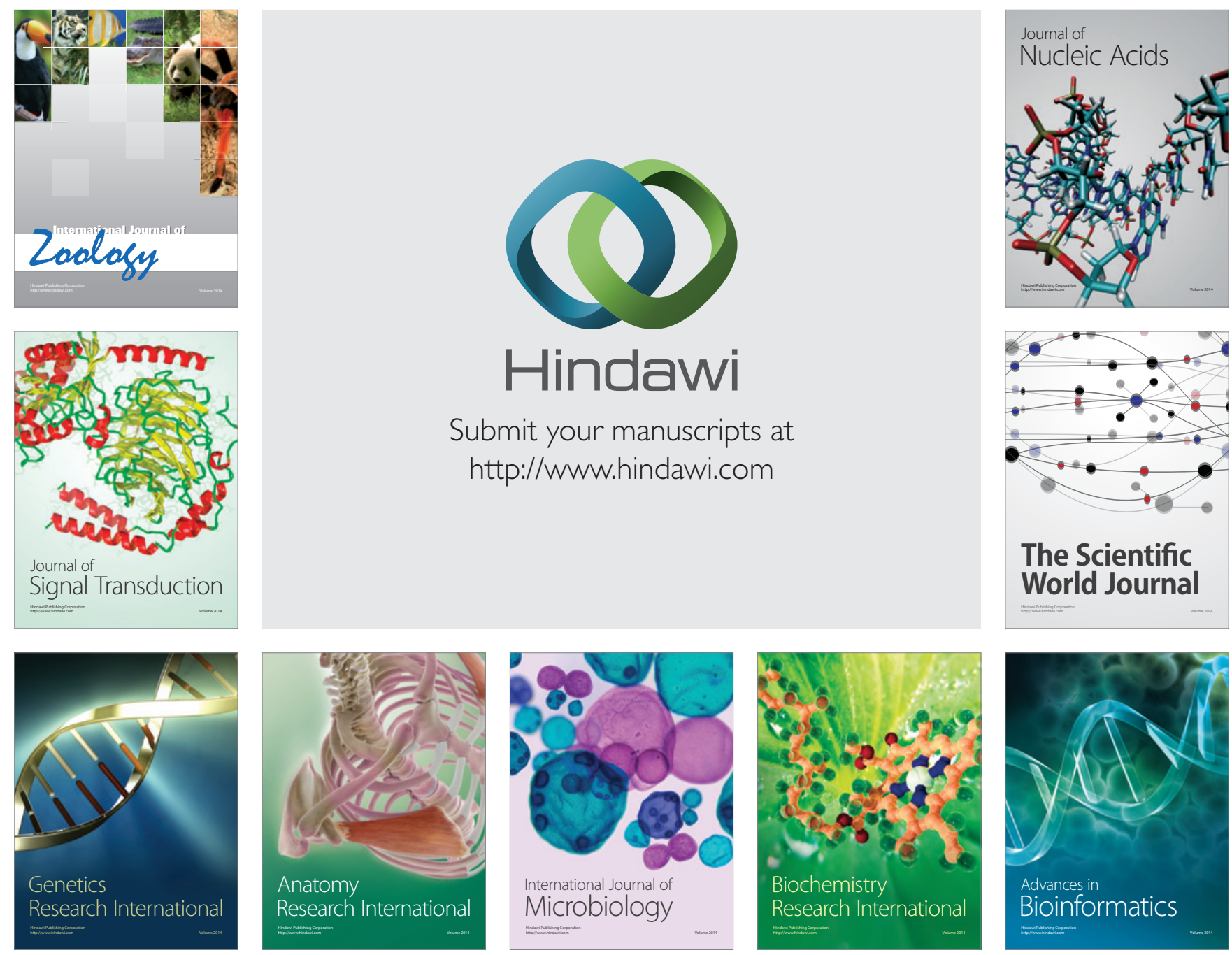

The Scientific World Journal
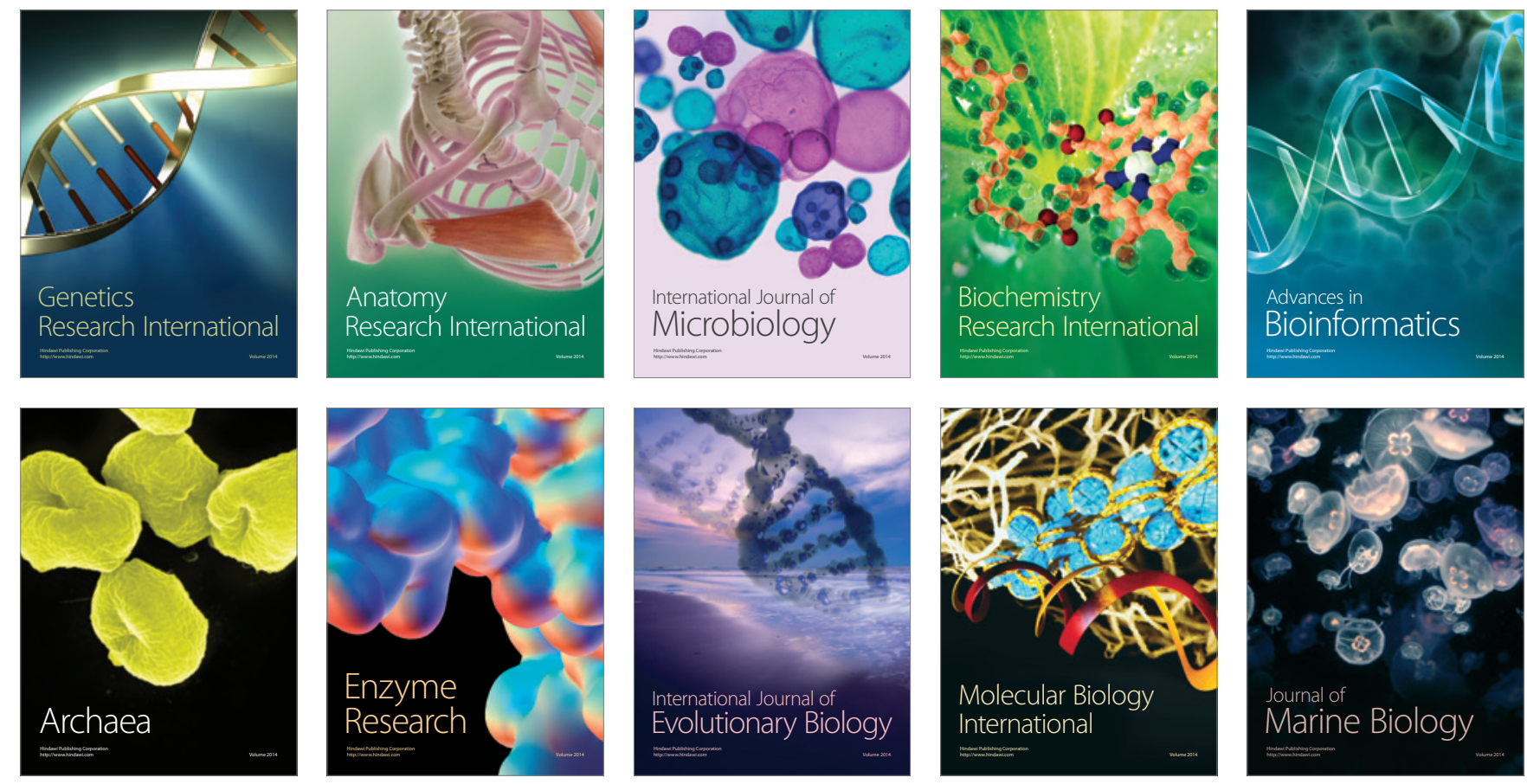